\title{
Effects of cannabis use on outcomes of psychotic disorders: systematic review
}

Stanley Zammit, Theresa H. M. Moore, Anne Lingford-Hughes, Thomas R. E. Barnes, Peter B. Jones, Margaret Burke and Glyn Lewis

\section{Background}

It is unclear if research findings support clinical opinion that cannabis use leads to worse outcomes in people with psychosis, or whether this impression is confounded by other factors.

\author{
Aims \\ To systematically review the evidence pertaining to whether \\ cannabis affects outcome of psychotic disorders.
}

\section{Method}

We searched 10 relevant databases (to November 2006), reference lists of included studies and contacted experts. We included 13 longitudinal studies from 15303 references. Data extraction and quality assessment were conducted independently and in duplicate.

\section{Results}

Cannabis use was consistently associated with increased relapse and non-adherence. Associations with other outcome measures were more disparate. Few studies adjusted for baseline illness severity, and most made no adjustment for alcohol, or other potentially important confounders. Adjusting for even a few confounders often resulted in substantial attenuation of results.

\section{Conclusions}

Confidence that most associations reported were specifically due to cannabis is low. Despite clinical opinion, it remains important to establish whether cannabis is harmful, what outcomes are particularly susceptible, and how such effects are mediated. Studies to examine this further are eminently feasible.

\section{Declaration of interest}

P.B.J. and T.R.E.B. were both invited experts on the Advisory Council on the Misuse of Drugs Cannabis Review in 2005. A.L.-H. has received an honorarium from Sanofi-Aventis for attending a meeting about cannabinoid antagonists. S.Z., P.B.J., T.R.E.B., G.L. and A.L.-H. have all received honoraria for lectures and talks, or consultancy fees (for work unrelated to cannabis) from pharmaceutical companies.
Cannabis use is more common in people with psychotic disorders compared with people without psychoses. ${ }^{1}$ This is perhaps surprising given the widely held clinical opinion that cannabis can cause deterioration or impair recovery from psychotic disorders.

Experimental studies and surveys of users provide evidence that cannabis intoxication can produce transient psychotic and affective experiences and can have detrimental effects on motivation and memory. ${ }^{2-4}$ Evidence from a recently conducted systematic review ${ }^{5}$ also indicates that cannabis may increase the incidence of psychotic outcomes, independently of intoxication effects. Given these effects on mental state, it seems plausible that continued use of cannabis following the onset of a psychotic disorder may increase the severity or duration of psychotic symptoms, decrease adherence to treatment and impair longer-term outcome.

One reason people with psychosis may use cannabis is that the perceived benefits such as a reduction in anxiety and increased sociability ${ }^{6,7}$ outweigh any perceived harmful consequences. However, it is also possible that the clinical impression of cannabis use resulting in a worse outcome in psychosis is confounded by other factors associated with poor prognosis such as alcohol or other illicit drug use.

Most studies that have examined the effects of substance use on psychosis have been either cross-sectional or case-control designs, but such approaches are limited, particularly in their ability to distinguish the direction of any associations observed. This ability to examine the direction of association is particularly important given the reports of increased cannabis use following onset of psychosis. ${ }^{8,9}$

In this review we examine the strength of evidence, from longitudinal studies, that cannabis use in people with psychosis impacts negatively on illness severity, adherence to treatment or other adverse outcomes, independently of the effects of alcohol and other drugs or other confounding factors.

\section{Method}

\section{Study samples}

Studies were included if they were longitudinal studies of people with psychosis, or case-control studies nested within longitudinal designs, where cannabis use was measured at a time prior to the outcome being measured. Cohorts of individuals with dual diagnosis of psychosis and cannabis misuse or dependence were excluded, as there could be no comparison group of people who did not use cannabis to determine if it had any affect on outcome.

The following diagnostic groups were included for psychosis: schizophrenia, schizophreniform, schizoaffective or psychotic disorders, non-affective or affective psychoses, psychosis not otherwise specified (NOS), psychotic symptoms, delusions, hallucinations or thought disorder. Primary outcomes that we specified a priori as being markers of progression of disease and relevant to this review were: relapse, readmission, change in symptom scores (positive, negative or global psychopathology symptoms), harm to self or others (including violence, criminality, suicide attempts and mortality), non-adherence to treatment, engagement with services, employment, homelessness, social functioning, quality of life and patient or carer satisfaction.

\section{Literature search}

We searched the following databases from their inception to November 2006: MEDLINE, EMBASE and the Cumulative Index to Nursing and Allied Health Literature (CINAHL) on OVID; PsycINFO on WebSPIRS; ISI Web of Knowledge and ISI Proceedings; Zetoc (British Library database of journal and conference contents); BIOSIS on EDINA; Latin American and Caribbean Health Sciences (LILACS); and Caribbean Health Sciences Literature (MedCarib). An experienced research librarian 
(M.B.) and three investigators (G.L. T.H.M.M and S.Z.) developed the search strategy. We searched using the format ((psychosis OR schizophrenia OR hallucinations OR delusions OR synonyms) AND (substance abuse AND synonyms)), using text words and indexing $(\mathrm{MeSH})$ terms (full details available from the authors on request). The search was restricted to studies on humans but not by language or publication status. We searched reference lists of included studies, and wrote to experts in the field and study authors to find other published and unpublished studies of relevance.

\section{Study selection and data extraction}

We examined all titles and abstracts, and obtained full texts of potentially relevant papers. Working independently and in duplicate, we read the papers to determine if they met our inclusion criteria using eligibility record forms. At the abstract stage we had more lenient inclusion criteria and included studies with broad descriptions of mental health problems and of drug use. These papers were obtained in full, and rejected if the data were not provided separately for people using cannabis or for people with psychotic disorder as defined by our criteria. Where information was only available as an abstract, authors were contacted for further information; if this was not forthcoming then the study was excluded. Disagreements were resolved by consensus, and data extracted independently and in duplicate.

\section{Quality assessment}

We assessed quality by recording how potential non-causal explanations, particularly bias and confounding, were accounted for in each study. We assessed information on sampling strategy, response rates, missing data, attrition and attempts to address reverse causation, intoxication effects and confounding. All relevant MOOSE (Meta-analysis Of Observational Studies in Epidemiology) guidelines ${ }^{10}$ were followed.

\section{Results}

\section{Description of studies}

\section{Results of search}

Our literature search, expert advice and search of reference lists yielded 15303 references. Of these, $226(1.5 \%)$ were thought to possibly have data relevant for our review, and 212 of these were excluded following a more detailed assessment using eligibility forms (Fig. 1).

\section{Included studies (for any outcome)}

We found 13 publications reporting data from 13 cohort studies. Seven studies examined first-episode or recent onset psychoses (onset within 5 years): the Brisbane $e^{9}$ and Melbourne ${ }^{11}$ studies in Australia (Melbourne study included after additional information provided by authors); the Calgary ${ }^{12}$ and Calgary Early Psychosis Program (CEPP $)^{13}$ studies in Canada; the South London Hospitals $^{14}$ and Manchester studies ${ }^{15}$ in the UK; and the HGDH research group study in first-episode psychosis, a multicentre trial based in both North America and Western Europe. ${ }^{16}$ Six studies included both incident and prevalent cases of psychosis: the Navarra ${ }^{17}$ study; the Madrid- $\mathrm{A}^{18}$ and the Madrid- $\mathrm{B}^{19}$ studies, all based in Spain; the Homburg ${ }^{20}$ study in Germany; and the Sydney- $\mathrm{A}^{21}$ and Sydney-B ${ }^{22}$ studies in Australia.

Results for the 13 studies are summarised in online Table DS1. Overall, of the 52 outcomes reported from these studies, cannabis was associated with statistical evidence of a worse outcome in 14 , and a better outcome in 7 of these. There was no evidence of association in either direction for the other 31 outcomes. Seven studies looked at people with schizophrenia only (or related spectrum disorders), but the other six included people with other psychoses too. All of the seven associations with better outcomes in cannabis users were in studies that included individuals with any psychosis rather than specifically schizophrenia or related spectrum disorders.

The variety in outcome and exposure measure definitions used, as well as the content of statistical results presented, meant that it was not possible to pool results in a meta-analysis, and we therefore use a narrative synthesis to summarise the findings from this systematic review.

\section{Excluded studies}

We identified five studies of people with psychosis that did not meet all our inclusion criteria but which we considered to be 'near-misses. ${ }^{23-27}$ These were all longitudinal studies but they either presented data only from cross-sectional analyses, or employed a measure of cannabis use that could have included individuals increasing or initiating use secondary to the outcome studied. All of these studies, including the seminal work by Linszen et $a l,{ }^{25}$ reported associations between cannabis use and worse outcomes. Further details of these studies are available at www.bristol.ac.uk/psychiatry/research/psychotic.html.

\section{Results for relapse or rehospitalisation}

We found four studies of relapse and three studies addressing rehospitalisation. Two studies used definitions for relapse based on the Brief Psychiatric Rating Scale (BPRS) scores; the Brisbane ${ }^{9}$ study reported a dose-response association between cannabis use (days per week) and increased relapse of psychosis, and a strong association between cannabis misuse and relapse was also reported in the Melbourne study. ${ }^{11}$ Relapse was also increased by cannabis use in the Navarra study, ${ }^{17}$ with evidence strongest for continued use during follow-up (64\% relapse in individuals using cannabis

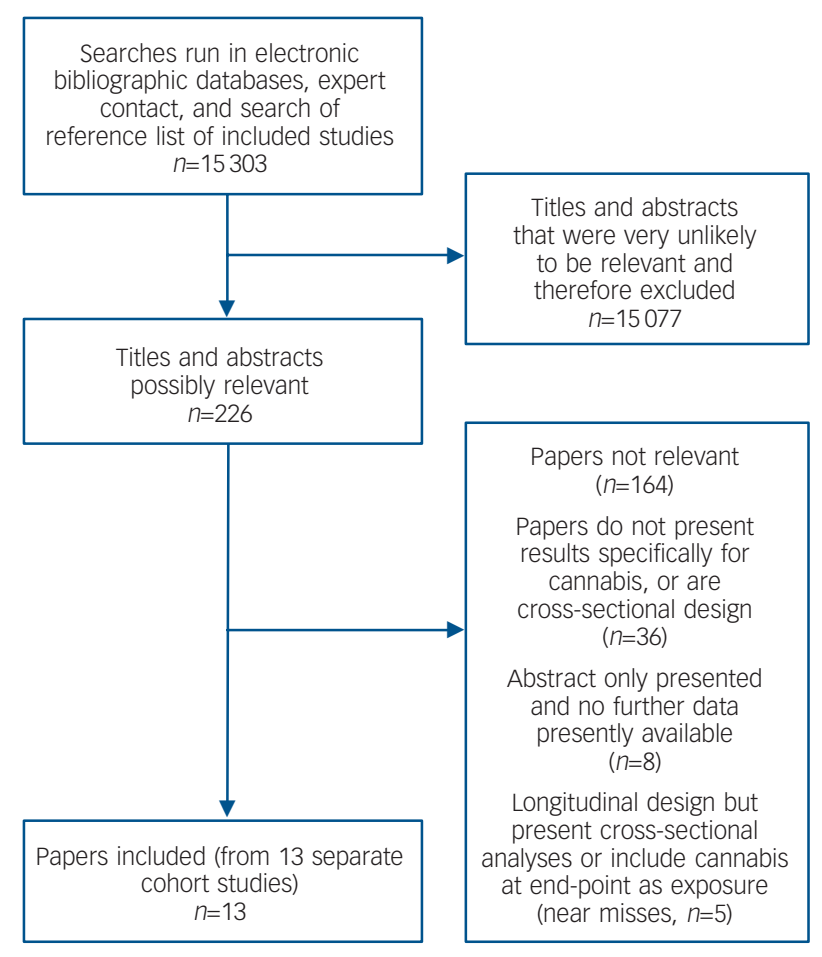

Fig. 1 QUOROM (Quality of Reporting of Meta-analyses) flow chart. 
at baseline and follow-up compared with $17 \%$ in non-users). Similarly, the Madrid-B study reported weak evidence for association between cannabis dependence and increased relapse. ${ }^{19}$ Neither of these two latter study reports provided the definition of relapse used.

Cannabis misuse was associated with a greater rehospitalisation index (0.98 readmissions per year compared with 0.35 for the non-misuse group) in the Homburg study, ${ }^{20}$ and similarly with a greater number of admissions in the Madrid-B study. ${ }^{19}$ In the Navarra study, risk of readmission was similar in individuals who used cannabis regularly at baseline only, but not at follow-up, compared with controls (13\% and $17 \%$ respectively), though there was some evidence for increased readmission in those using cannabis regularly both at baseline and at follow-up $(43 \%$ v. $17 \%, P=0.08){ }^{17}$

\section{Results for severity of symptoms}

Overall we identified seven studies that examined psychopathology symptom scores that included measures of psychosis, mood, aggression and cognitive function. The $\mathrm{HGDH}^{16}$ study, a treatment trial of olanzapine $v$. haloperidol in first-episode schizophrenia, and the Sydney-A study ${ }^{21}$ were the only studies to measure change in symptom scores from baseline to follow-up or adjust for baseline scores.

\section{Positive symptoms}

In the Sydney-A study, ${ }^{21}$ cannabis use was associated with a small increase in BPRS score that persisted after adjusting for prior BPRS scores. In the HGDH study, cannabis misuse was not significantly associated with a change in the Positive and Negative Syndrome Scale (PANSS) total score from baseline to follow-up in either of the two trial arms of the study. ${ }^{16}$ However, change in score was less in both arms for the cannabis misuse group compared with non-users, though no combined analysis of the two trial groups was presented, thereby reducing statistical power.

Regular cannabis use at baseline was associated with increased level of positive symptoms at follow-up in the South London Hospitals study, ${ }^{14}$ and in the Homburg study ${ }^{20}$ cannabis misuse was associated with 2 of 12 symptom sub-scales examined (increased thought disturbance and hostility). Cannabis was not associated with the positive symptom sub-scale of the PANSS in the Madrid-B study ${ }^{19}$ or with scores on the Scale for the Assessment of Positive Symptoms (SAPS) in the Manchester study. ${ }^{15}$

\section{Negative symptoms}

Regular cannabis use was not associated with negative symptoms scores in the South London Hospitals, ${ }^{14}$ the Manchester, ${ }^{15}$ or the Homburg $^{20}$ studies. However, an association between cannabis dependence and a reduced score on the PANSS negative symptom scale at follow-up was observed in the Madrid-B study. ${ }^{19}$

\section{Other measures}

Cannabis misuse was not associated with depression score in the Sydney-A study, ${ }^{21}$ with anxiety or depression sub-scales used in the Homburg study, ${ }^{20}$ or with Overt Aggression Scale score in the Madrid-A study. ${ }^{18}$ Neurocognitive ability at follow-up was greater on five out of nine sub-scales in people who had used cannabis at baseline in the Manchester study. ${ }^{15}$

\section{Results for measures of response to treatment}

A variety of other outcomes reflecting response to treatment were investigated in these studies. These included symptom score defined response to treatment, ${ }^{16}$ length of in-patient stay, ${ }^{22}$ course of illness, ${ }^{14}$ presence of deficit schizophrenia, ${ }^{15}$ global assessment scale (GAS) score, ${ }^{20}$ service contact, ${ }^{15}$ productivity or employment, ${ }^{12,20}$ marital status, ${ }^{20}$ living alone ${ }^{20}$ and quality of life. ${ }^{12}$

In the South London Hospitals study ${ }^{14}$ there was some evidence that individuals who had used cannabis frequently at baseline had a more continuous course of illness than people who had not used cannabis regularly (crude odds ratio $(\mathrm{OR})=2.4$, 95\% CI 0.9-6.9). Cannabis was not associated with treatment non-response in the HGDH study, ${ }^{16}$ or with service contact or GAS score in the Manchester ${ }^{15}$ and Homburg ${ }^{20}$ studies respectively.

In the Calgary study, ${ }^{12}$ cannabis use at baseline was associated with decreased levels of productivity or employment, as well as reduced quality-of-life measures at follow-up. There was suggestive evidence that people who used cannabis in the Homburg study ${ }^{20}$ were more likely to be single and less likely to be employed or living alone than individuals who did not use cannabis, though none of these associations were statistically significant.

Two studies also observed associations between cannabis use and improved outcomes; in the Manchester study ${ }^{15}$ a state of deficit schizophrenia was less common in people who had used cannabis at baseline compared with non-users, and in the Sydney-B study ${ }^{22}$ there was weak evidence that cannabis use at baseline was associated with a clinically important shorter duration of admission ( 13 days $v .21$ days, $P=0.07$ ).

\section{Results for adherence to treatment}

Three studies examined cannabis use in relation to subsequent adherence to treatment. In the Madrid-B study ${ }^{19}$ cannabis dependence at baseline was associated with non-adherence during follow-up. A dose-response model of increasing baseline cannabis use in the CEPP study ${ }^{13}$ was also associated with increased levels of non-adherence in the crude analysis, though this association was eliminated after adjustment for confounding. Similarly in the Navarra study, ${ }^{17}$ continued cannabis use during follow-up (but not use of cannabis at baseline only) was weakly associated with reduced adherence compared with non-users (36\% v. 67\%, $P=0.06$ ).

\section{Methodological quality of included studies}

We assessed the degree to which the potential effect of confounding and bias were minimised within each study (summarised in Table 1). Although a number of factors could have led to overestimation of the true causal association between cannabis use and poorer outcomes of psychosis in these studies, perhaps the most likely of these is confounding, particularly by use of alcohol and other drugs; and baseline measures of illness severity and level of functioning (that may have led to reverse causation effects).

Of the 13 studies included in this review, only five studies (Brisbane, ${ }^{9}$ Melbourne $^{11}$, Navarra, ${ }^{17}$ Sydney-A ${ }^{21}$ and $\mathrm{HGDH}^{16}$ ) made any adjustment for measures of illness severity at baseline. Only three studies (Brisbane, ${ }^{9}$ Melbourne ${ }^{11}$ and Madrid- ${ }^{19}{ }^{19}$ ) adjusted for both alcohol and other drug use, though this was for only one of the five outcomes in the Madrid-B study. In the Homburg study ${ }^{20}$ some adjustment for alcohol and other drug use was done by exclusion of individuals mainly using drugs other than cannabis. In the Sydney-A study, ${ }^{21}$ alcohol and other drug use were excluded from the adjusted model as they were not associated with the outcome, and were therefore unlikely to have substantially confounded the relationship with cannabis. One study adjusted for alcohol use only (CEPP),${ }^{13}$ and one other 


\begin{tabular}{|c|c|c|c|c|c|c|}
\hline $\begin{array}{l}\text { Cohort } \\
\text { label }\end{array}$ & $\begin{array}{l}\text { Response rate } \\
\text { at baseline }\end{array}$ & $\begin{array}{l}\text { Loss to } \\
\text { follow-up, \% }\end{array}$ & $\begin{array}{l}\text { Masking of outcome } \\
\text { assessment }\end{array}$ & $\begin{array}{l}\text { Adjusted for baseline } \\
\text { illness severity }\end{array}$ & $\begin{array}{l}\text { Adjusted for alcohol } \\
\text { and other drugs }\end{array}$ & $\begin{array}{l}\text { Impact of adjusting } \\
\text { for confounders }\end{array}$ \\
\hline Brisbane $^{9}$ & $\begin{array}{l}88 \% \text { of participants } \\
\text { approached }\end{array}$ & 15 & No & Yes & Yes & $\begin{array}{l}\text { Association persisted } \\
\text { after adjustment, but no } \\
\text { indication as to extent of } \\
\text { confounding }\end{array}$ \\
\hline Calgary $^{12}$ & Not mentioned & 29 & No & No & No & $\begin{array}{l}\text { Some associations } \\
\text { eliminated after adjust- } \\
\text { ing for symptoms at } \\
\text { follow-up }\end{array}$ \\
\hline CEPP 13 & $\begin{array}{l}\text { All first } 200 \text { incident } \\
\text { cases }\end{array}$ & 22 & No & No & $\begin{array}{l}\text { Adjusted for alcohol } \\
\text { use }\end{array}$ & $\begin{array}{l}\text { Association with base- } \\
\text { line cannabis use elimi- } \\
\text { nated by adjustment }\end{array}$ \\
\hline $\mathrm{HGDH}^{16}$ & Not mentioned & 0.4 & No & $\begin{array}{l}\text { Yes for } 1 \text { of } 2 \\
\text { outcomes (measured } \\
\text { score change) }\end{array}$ & No & Not assessed \\
\hline Homburg ${ }^{20}$ & $\begin{array}{l}\text { All those identified } \\
\text { as cases included }\end{array}$ & $\begin{array}{l}\text { Cannabis misuse } \\
\text { group, 31; non- } \\
\text { misuse group, } 33\end{array}$ & No & No & $\begin{array}{l}\text { Some adjustment, as } \\
\text { cases excluded if mainly } \\
\text { used drugs other than } \\
\text { cannabis }\end{array}$ & Not assessed \\
\hline Madrid-A ${ }^{18}$ & 63 of 70 eligible (90\%) & 0 & No & No & No & Not assessed \\
\hline Madrid-B $^{19}$ & Not mentioned & 0 & No & No & $\begin{array}{l}1 \text { of } 5 \text { outcomes studied } \\
\text { was adjusted for alcohol/ } \\
\text { other drugs }\end{array}$ & Not assessed \\
\hline Manchester $^{15}$ & $100 \%$ & 38 & No & No & No & $\begin{array}{l}\text { Associations for } 2 \text { cog- } \\
\text { nitive tests eliminated } \\
\text { after adjusting for age } \\
\text { at onset; } 5 \text { other } \\
\text { associations persisted }\end{array}$ \\
\hline Melbourne $^{11}$ & Not mentioned & 18 & No & Yes & Yes & $\begin{array}{l}\text { Reduced estimate by } \\
15 \%\end{array}$ \\
\hline Navarra $^{17}$ & $94 \%$ & 17 & No & No & $\begin{array}{l}\text { No. Cannabis use was } \\
\text { associated with alcohol } \\
\text { and other drug misuse } \\
\text { in sample }\end{array}$ & Not assessed \\
\hline $\begin{array}{l}\text { South London } \\
\text { Hospitals }^{14}\end{array}$ & $\begin{array}{l}119 \text { with baseline data } \\
\text { from } 227 \text { consecutive } \\
\text { admissions (52\%) }\end{array}$ & 18 & $\begin{array}{l}\text { Masked to baseline } \\
\text { cannabis; unclear } \\
\text { if masked to } \\
\text { follow-up use }\end{array}$ & No & No & $\begin{array}{l}\text { Reduced estimates by } \\
\text { approximately } 20-80 \%\end{array}$ \\
\hline Sydney-A $\mathrm{A}^{21}$ & Not mentioned & $\begin{array}{l}22 \text { for psychosis } \\
\text { outcome } \\
\text { observations }\end{array}$ & No & Yes & $\begin{array}{l}\text { No, but alcohol and other } \\
\text { drugs had non-significant } \\
\text { effect on outcome and } \\
\text { thus omitted from final } \\
\text { model }\end{array}$ & $\begin{array}{l}\text { Reduced estimate by } \\
35 \%\end{array}$ \\
\hline Sydney-B ${ }^{22}$ & $\begin{array}{l}\text { Out of } 167 \text { patients, } \\
45 \text { had drug screens } \\
\text { done }(27 \%)\end{array}$ & 0 & No & No & $\begin{array}{l}\text { No other illicit substances } \\
\text { detected in urine for whole } \\
\text { of sample, but no adjust- } \\
\text { ment for alcohol misuse }\end{array}$ & \\
\hline
\end{tabular}

$(\text { Sydney-B) })^{22}$ made some adjustment for other drug (but not alcohol) use.

A further potential mechanism by which overestimates of association may have resulted is by lack of masking of exposure status when assessing outcome. In fact, a statement that outcome measurement was performed masked to cannabis exposure was only evident in one of the studies (South London Hospitals). ${ }^{14}$ A summary of study quality issues in relation to the different outcomes studied is presented below.

\section{Studies of relapse or rehospitalisation}

Relapse of psychosis as defined for the Brisbane $e^{9}$ and Melbourne ${ }^{11}$ studies (and as implied for the Navarra study ${ }^{17}$ ) required a change in symptom severity between baseline and follow-up, reducing, though not eliminating, the possibility of confounding by factors related to illness severity. Furthermore, in the Brisbane study ${ }^{9}$ results were adjusted for a wide range of potentially important confounders, including baseline symptoms, alcohol and drug use, and measures of social functioning and family environment. Results for the Melbourne study ${ }^{11}$ were adjusted for baseline symptoms and for alcohol and other drug use, and results for the Navarra study ${ }^{17}$ were adjusted for adherence and life stresses.

None of the studies that examined rehospitalisation however made any adjustment for illness severity at the time of discharge from the index admission, or for markers of social function or socio-demographic status (apart for adjustment for age and gender in the Homburg study ${ }^{20}$ ).

\section{Studies of symptom scores}

For the studies that examined symptom scores as outcomes, only two studies adjusted for baseline scores or examined change in scores from baseline to follow-up (Sydney-A $\mathrm{A}^{21}$ and $\mathrm{HGDH}^{16}$ ). 
None of the five other studies reporting associations between cannabis and symptom severity at follow-up took into account levels of symptom severity at baseline. In the Manchester study ${ }^{15}$ there was a strong association between cannabis use and fewer neurological soft signs at baseline, though this was not adjusted for in the associations reported with neurocognitive outcomes.

\section{Studies of response to treatment}

With regard to measures of response to treatment, course of illness as examined in the South London Hospitals study ${ }^{14}$ implies change of symptom severity during follow-up and adjustments for age, gender and ethnicity were also made in this study. In the Manchester study ${ }^{15}$ there were no significant baseline differences in negative symptoms or social adjustment, indicating that the association with deficit schizophrenia is perhaps unlikely to be confounded by these. No adjustments for baseline severity of illness, or any other confounders however were made in the Sydney-B study, ${ }^{22}$ where a weak association with length of in-patient admission was reported. Similarly in the Calgary ${ }^{12}$ and Homburg ${ }^{20}$ studies, no adjustments were made for level of productivity or quality of life at baseline, or for baseline marital, employment or accommodation status, when examining for associations with these measures at follow-up.

\section{Studies of adherence}

The CEPP study $^{13}$ results were adjusted for a wide range of potentially important confounders, but no adjustment for any confounders in relation to this outcome was done in the Madrid-B ${ }^{19}$ or the Navarra ${ }^{17}$ studies.

\section{Discussion}

As far as we are aware this is the first systematic review to examine whether use of cannabis has a detrimental effect on outcome in people suffering from a psychotic illness. We found relatively few longitudinal studies that have examined this hypothesis.

Use of cannabis was associated with increased relapse or rehospitalisation and with decreased treatment adherence fairly consistently across the studies that examined these outcomes. Associations between cannabis and psychotic symptoms or other psychopathology scores were more inconsistent, with only three studies presenting evidence of association with increased positive symptoms and one study reporting an association with decreased negative symptoms. Definitions for relapse in two studies ${ }^{9,11}$ were based on increases in positive symptoms scores however, and both of these studies found evidence that cannabis use led to increased relapse. Evidence for associations with other measures of treatment response was also quite discrepant, with some studies reporting negative outcomes of reduced quality of life, productivity or a more continuous illness course in people using cannabis, but other studies reported associations with positive outcomes including shorter in-patient stays and reduced deficit schizophrenia in cannabis users.

\section{Examination of non-causal explanations for association}

The most important consideration when attempting to interpret the findings of this review is the methodological quality of the studies included in relation to bias and confounding. Only four of the thirteen studies (Brisbane, ${ }^{9}$ Melbourne, ${ }^{11}$ Sydney- $\mathrm{A}^{21}$ and $\mathrm{HGDH}^{16}$ ) made any attempt to adjust for baseline illness severity measures. Access to, and use of cannabis, may be associated with premorbid level of functioning or illness severity, both of which are also likely to be related to clinical outcome.

Furthermore, even basic socio-demographic characteristics such as social class or gender that are associated both with poor outcome $^{28,29}$ and with cannabis use $e^{30,31}$ were only adjusted for in six of the studies. Most studies made no adjustment for alcohol or other drug use, though these are strongly associated with detrimental mental health outcomes ${ }^{32,33}$ and are therefore also likely to be confounders. They are also likely to serve as markers of other factors such as personality traits relating to risk taking and adherence with medical advice that could further confound the relationship between cannabis and outcome in psychosis. These methodological issues are particularly pertinent given that non-adherence is likely to result in poorer clinical outcomes generally.

Although some adjustment for confounding was undertaken in a number of studies, only the Melbourne, ${ }^{11}$ South London Hospitals $^{14}$ and Sydney- $\mathrm{A}^{21}$ studies presented both crude and adjusted estimates that enable us to gauge the potential impact of confounding in these studies. Estimates were attenuated by between $15 \%$ and $80 \%$, although only a limited number of potentially important confounders were adjusted for in these studies. Given that the range of confounders adjusted for was rather incomprehensive in most of the studies included in this review, confidence that the associations reported are specifically due to cannabis in these studies must therefore be rather low.

Clinical opinion has long been that use of cannabis results in a worse outcome in people with psychotic illnesses and the original study in this field by Linszen et al ${ }^{25}$ lent strong support to this view. This makes it particularly important that studies measure outcomes masked to cannabis exposure status to avoid overestimation of association due to observer measurement bias. The South London Hospitals study ${ }^{14}$ was the only study to report such masking.

Reverse causation was unlikely to have been a problem as we only included longitudinal studies in this review. The Calgary, ${ }^{12}$ $\mathrm{CEPP}^{13}$ and South London Hospitals ${ }^{14}$ studies however also included some results for measures of cannabis use at follow-up. Results for these measures (that showed stronger associations than for use at baseline only) were therefore omitted, as these associations could have resulted, in part, from reverse causation effects. On the other hand, results for individuals using cannabis at baseline but not at follow-up are likely to be underestimates of true effects of cannabis as they ignore the impact of continued use. However, following such a conservative approach for these studies seemed preferable in order to firmly establish direction of causality.

If cannabis is indeed a risk factor for causing psychotic illnesses ${ }^{5}$ then it is perhaps surprising that these studies of the effects of cannabis on clinical outcome are so inconsistent, especially as our assessment of methodological quality suggests that insufficient attention was paid to addressing overestimation of causal effects in these studies.

\section{Possible reasons for lack of evidence for association}

It is also possible that studies underestimated the true impact of cannabis on the outcome of psychosis. Random misclassification of data is probably the most likely reason for underestimation of association. In particular, self-report measures of cannabis use are unlikely to accurately reflect the dose of psychoactive cannabinoids available in the brain given variations in potency of cannabis used, and amounts of cannabinoids inhaled and metabolised. Misclassification in accuracy of reporting is also 
likely, although in the Brisbane study ${ }^{9}$ self-reports of cannabis use (as used in the analyses) showed good reliability with drug screens in a subsample of the cohort (Cohen's kappa $=0.90$ ). Repeated and detailed assessment of cannabis exposure during the follow-up period, but before outcome measurement, would help to reduce misclassification. However, most studies to date have used rather limited assessments of cannabis exposure, measured only before the follow-up period started.

Furthermore, loss to follow-up in cohort studies tends to be greater for individuals who have more severe mental health problems and for those with substance misuse. Such an effect of differential attrition would have led to underestimation of the strength of any association. The median loss to follow-up for these studies was $17 \%$ (range 0-38\%), though the only study (Homburg ${ }^{20}$ ) that examined whether attrition was different for cannabis using and non-using groups reported minimal difference across the two groups.

Apart from the possible effects of bias, lack of statistical power could also have led to lack of evidence for associations in some of these studies. None of the studies that failed to observe associations between cannabis use and clinical outcomes presented power calculations. If we assume that $20 \%$ of patients with psychosis relapse over a 1-year period if they do not use cannabis and $40 \%$ relapse if they use cannabis regularly, and that $25 \%$ of patients use cannabis regularly, then a power calculation indicates that a sample size of over 250 people with psychosis is required to have $80 \%$ power to detect this effect. This calculation is based on a large difference in relapse rates between cannabis users and non-users, and yet only one of the studies included in this review meets this required sample size.

Finally, it is also possible that variation in the diagnostic composition of the participants with psychoses across different studies, as well as differences in the measures of clinical outcome and definitions of cannabis exposure, might partly explain the diverse and at times conflicting results reported. For example, all of the associations between cannabis use and better outcomes were in studies that included individuals with any psychotic diagnosis, while studies of people with schizophrenia or related spectrum disorders appear to show more consistent evidence for poorer outcomes in those using cannabis.

\section{Limitations}

Although we identified a large number of potential studies for inclusion, most studies were not set up to directly address the aim of this review and were not able to meet our criteria for inclusion. As well as the possibility that we missed some studies during our searches, we excluded a large number of studies by requiring studies to be of longitudinal design as these provide the most reliable evidence for causal association in the absence of randomised controlled trials. Furthermore, the rather insubstantial nature of what constitutes a 'poor clinical outcome' means that it is more difficult to summarise results of studies in this review compared, for example, with reviews where disease incidence is the studied outcome.

We also excluded a large number of studies that examined the effects of substance use in general rather than specifically use of cannabis. As cannabis is the most frequently used illicit substance in most countries it could be argued that results for substance use (that excludes alcohol or tobacco) mainly reflect the effects of cannabis. However, even in such situations, the possibility of strong confounding by other drugs remains. Furthermore, although uncommon, substance use may at times be dominated by stimulant drugs such as amphetamines or cocaine. ${ }^{34}$

\section{Implications for future research and clinical practice}

Given that psychoactive compounds within cannabis can cause or increase psychotic experiences secondary to intoxication effects, ${ }^{2,3}$ and independently of such effects, ${ }^{5}$ it is very plausible that cannabis might lead to increased positive symptoms and subsequently relapse or rehospitalisation in people with psychosis. Indeed, there is a widespread belief among psychiatrists that such a detrimental effect does exist. We were surprised how little empirical evidence is currently available to support this view. Our assessment of methodological quality suggests that although insufficient attention was paid to addressing overestimation of causal effects, low statistical power to observe associations was also likely to have been present in many of the studies.

Despite the clinical consensus and the plausibility of harmful effects, we believe it is important to establish whether cannabis is harmful, and if so, what the size of any harmful effect is. Trials of interventions for reducing cannabis use in people with psychosis may provide stronger evidence of possible detrimental effects of this drug, as this would be independent of confounding effects.

We also need to know what kinds of outcome are particularly susceptible to the influence of cannabis; whether clinical, employment status or other aspects of social functioning. An understanding of the effects of different potency preparations as well as of pattern of exposure is also required. Comparing the effects of cannabis with other psychoactive drugs would enable clinicians and patients to prioritise harm reduction plans.

Although most of the associations reported were with markers of poorer clinical outcome, some studies also reported better outcomes in individuals using this drug. It is possible that cannabis has differential effects on different outcomes, for example worsening positive symptoms but improving negative ones. Further research on the specific effects of cannabis on such outcomes may help our understanding of aetiological mechanisms, further elucidate why some individuals with psychosis choose to use cannabis, and suggest approaches that might be used by clinicians to engage this problem. Understanding to what extent any associations are mediated through indirect pathways resulting in poor outcome, such as reduced adherence, may also enable more specific targeting of focused interventions to improve long-term care in people with psychotic disorders.

Insufficient empirical evidence exists at present to adequately examine whether cannabis use has detrimental effects on the outcome of psychotic disorders, or to determine the pathways by which such effects are mediated, although these are important and clinically relevant questions.

Future studies to address these uncertainties should be of longitudinal design, with repeated measures of psychopathology, use of cannabis, alcohol and other substances, as well as baseline measures of function, illness severity and other characteristics that are known to be associated with poorer outcome in schizophrenia. Appropriate analyses should ensure that reverse causation effects are minimised, for example by using time-lagged measures of cannabis use where repeated measures are available. Reporting of both crude and adjusted estimates, with specific reporting as to which specific confounders have the greatest impact on the results would aid design of future studies. Use of clearly defined diagnostic categories and a more universal approach to measures of cannabis exposure and outcomes (that are measured masked to exposure status) would further help with interpreting and summarising future study findings.

Unlike the situation that exists for examining causal effects of cannabis on incidence of psychosis, adequately powered longitudinal studies of outcome of people with psychosis should be, 
in comparison, relatively easy to carry out given the widespread availability of large clinical samples.

\section{Stanley Zammit, PhD, Academic Unit of Psychiatry, University of Bristol, and} Department of Psychological Medicine, Cardiff University; Theresa H. M. Moore MSc, BSc, Anne Lingford-Hughes, BM, BCh, PhD, Academic Unit of Psychiatry, University of Bristol; Thomas R. E. Barnes, MD, DSC, Department of Psychological Medicine, Imperial College London; Peter B. Jones, MD, PhD, Department of Psychiatry, Cambridge University; Margaret Burke, BA, MSC, Department of Social Medicine, University of Bristol; Glyn Lewis, PhD, Academic Unit of Psychiatry, University of Bristol, UK

Correspondence: Stanley Zammit, Department of Psychiatry, Cardiff University , Heath Park, Cardiff CF14 4XN, UK. Email: zammits@cardiff.ac.uk

First received 16 Oct 2007, final revision 5 May 2008, accepted 19 Jun 2008

\section{Acknowledgements}

We would like to thank the authors of the papers we considered for inclusion in our review Cheryl Corcoran, Marie-Odile Krebs, Martin Lambert, John Stirling and Ingrid Melle for their helpful correspondence; and Blanca Bolea, Jorge Gaete and Juan Santos for help with helpful correspondence; and Blanca Bolea, Jorge Gaete and Juan Santos for help with
translation. We are especially grateful to Jean Addington and Darryl Wade for providing us with additional data for us to consider for inclusion in our review.

This work was funded by the Department of Health, UK. S.Z. is funded through a Clinician Scientist Award funded by the National Assembly for Wales.

\section{References}

1 Hall W, Degenhardt L. Cannabis use and psychosis: a review of clinical and epidemiological evidence. Aust N Z J Psychiatry 2000; 34: 26-34.

2 D'Souza DC, Abi-Saab WM, Madonick S, Forselius-Bielen K, Doersch A, Braley G, Gueorguieva R, Cooper TB, Krystal JH. Delta-9-tetrahydrocannabinol effects in schizophrenia: implications for cognition, psychosis, and addiction. Biol Psychiatry 2005; 57: 594-608.

3 D'Souza DC, Perry E, MacDougall L, Ammerman Y, cooper T, Wu YT, Braley G, Gueorguieva R, Krystal JH. The psychotomimetic effects of intravenous delta-9-tetrahydrocannabinol in healthy individuals: implications for psychosis. Neuropsychopharmacol 2004; 29: 1558-72.

4 Thomas H. A community survey of adverse effects of cannabis use. Drug Alcohol Depend 1996; 42: 201-7.

5 Moore TH, Zammit S, Lingford-Hughes A, Barnes TR, Jones PB, Burke M, Lewis G. Cannabis use and risk of psychotic or affective mental health outcomes: a systematic review. Lancet 2007; 370: 319-28.

6 Dixon L, Haas G, Weiden P, Sweeney J, Frances A. Acute effects of drug abuse in schizophrenic patients: Clinical observations and patients' selfreports. Schizophr Bull 1990; 16: 69-79.

7 Schofield D, Tennant C, Nash L, Degenhardt L, Cornish A, Hobbs C, Brennan G. Reasons for cannabis use in psychosis. Aust N Z J Psychiatry 2006; 40: 570-4.

8 Ferdinand RF, Sondeijker F, van der Ende J, Selten JP, Huizink A, Verhulst FC. Cannabis use predicts future psychotic symptoms, and vice versa. Addiction 2005; 100: 612-8.

9 Hides L, Dawe S, Kavanagh DJ, Young McD R. A prospective study of psychotic symptom and cannabis relapse in recent onset psychosis. Br J Psychiatry 2006; 189: 137-43.

10 Stroup DF, Berlin JA, Morton SC, Olkin I, Williamson GD, Rennie D, Moher D Becker BJ, Sipe TA, Thacker SB. Meta-analysis of observational studies in epidemiology: a proposal for reporting. Meta-analysis of Observational Studies in Epidemiology (MOOSE) group. JAMA 2000; 283: 2008-12.

11 Wade D, Harrigan S, Edwards J, Burgess PM, Whelan G, McGorry PD. Substance misuse in first-episode psychosis: 15-month prospective follow-up study. Br J Psychiatry 2006; 189: 229-34.

12 Pencer A, Addington J, Addington D. Outcome of a first episode of psychosis in adolescence: a 2-year follow-up. Psychiatry Res 2005; 133: 35-43.
13 Coldham EL, Addington J, Addington D. Medication adherence of individuals with a first episode of psychosis. Acta Psychiatr Scand 2002; 106: 286-90.

14 Grech A, van Os J, Jones PB, Lewis SW, Murray RM. Cannabis use and outcome of recent onset psychosis. Eur Psychiatry; 20: 349-53.

15 Stirling J, Lewis S, Hopkins R, White C. Cannabis use prior to first onset psychosis predicts spared neurocognition at 10-year follow-up. Schizophr Res 2005; 75: 135-7.

16 Green Al, Tohen MF, Hamer RM, Strakowski SM, Lieberman JA, Glick I, Clark WS; HGDH Research Group. First episode schizophrenia-related psychosis and substance use disorders: acute response to olanzapine and haloperidol. Schizophr Res 2004; 66: 125-35.

17 Martinez-Arevalo MJ, Calcedo-Ordonez A, Varo-Prieto JR. Cannabis consumption as a prognostic factor in schizophrenia. Br J Psychiatry 1994; 164: 679-81.

18 Arango C, Calcedo BA, Gonzalez S, Calcedo OA. Violence in inpatients with schizophrenia: a prospective study. Schizophr Bull 1999; 25: 493-503.

19 Arias Horcajadas F, Romero SS, Calo JJP. Relevance of drug use in clinical manifestations of schizophrenia [Spanish]. Actas Esp Psiquiatr 2002; 30: 65-73.

20 Caspari D. Cannabis and schizophrenia: results of a follow-up study. Eur Arch Psychiatry Clin Neurosci 1999; 249: 45-9.

21 Degenhardt L, Tennant C, Gilmour S, Schofield D, Nash L, Hall W, McKay D. The temporal dynamics of relationships between cannabis, psychosis and depression among young adults with psychotic disorders: findings from a 10-month prospective study. Psychol Med 2007; 37: 1-8.

22 Grace RF, Shenfield G, Tennant C. Cannabis and psychosis in acute psychiatric admissions. Drug Alcohol Rev 2000; 19: 287-90.

23 Addington J, Addington D. Patterns, predictors and impact of substance use in early psychosis: a longitudinal study. Acta Psychiatr Scand 2007; 115: 304-9.

24 Arseneault L, Moffitt TE, Caspi A, Taylor PJ, Silva PA. Mental disorders and violence in a total birth cohort: results from the Dunedin Study. Arch Gen Psychiatry 2000; 57: 979-86.

25 Linszen DH, Dingemans PM, Lenior ME. Cannabis abuse and the course of recent-onset schizophrenic disorders. Arch Gen Psychiatry 1994; 51: 273-9.

26 Linszen DH, Dingemans PM, Nugter MA, Van der Does AJ, Scholte WF, Lenior MA. Patient attributes and expressed emotion as risk factors for psychotic relapse. Schizophr Bull 1997; 23: 119-30.

27 Pencer A, Addington J. Substance use and cognition in early psychosis. J Psychiatry Neurosci 2003; 28: 48-54.

28 Lauronen E, Miettunen J, Veijola J, Karhu M, Jones PB, Isohanni M. Outcome and its predictors in schizophrenia within the Northern Finland 1966 Birth Cohort. Eur Psychiatry 2007; 22: 129-36.

29 Munk-Jorgensen $\mathrm{P}$, Mortensen PB. Social outcome in schizophrenia: a 13-year follow-up. Soc Psychiatry Psychiatr Epidemiol 1992; 27: 129-34.

30 Hofler M, Lieb R, Perkonigg A, Schuster P, Sonntag H, Wittchen HU. Covariates of cannabis use progression in a representative population sample of adolescents: a prospective examination of vulnerability and risk factors. Addiction 1999; 94: 1679-94.

31 von Sydow K, Lieb R, Pfister H, Hofler M, Wittchen HU. What predicts incident use of cannabis and progression to abuse and dependence? A 4-year prospective examination of risk factors in a community sample of adolescents and young adults. Drug Alcohol Depend 2002; 68: 49-64.

32 Jane-Llopis E, Matytsina I. Mental health and alcohol, drugs and tobacco: a review of the comorbidity between mental disorders and the use of alcohol, tobacco and illicit drugs. Drug Alcohol Rev 2006; 25: 515-36.

33 Regier DA, Farmer ME, Rae DS, Locke BZ, Keith SJ, Judd LL, Goodwin FK. Comorbidity of mental disorders with alcohol and other drug abuse. Results from the Epidemiologic Catchment Area (ECA) Study. JAMA 1990; 264 : 2511-8.

34 Mueser KT, Yarnold PR, Bellack AS. Diagnostic and demographic correlates of substance abuse in schizophrenia and major affective disorder. Acta Psychiatr Scand 1992; 85: 48-55. 